\title{
Caregiver knowledge, attitudes, and practices regarding childhood diarrhea and dehydration in Kingston, Jamaica
}

\author{
Lela Rose Bachrach ${ }^{1}$ and Julie Meeks Gardner ${ }^{2}$
}

ABSTRACT Objective. To study the knowledge, attitudes, and practices of caregivers in Kingston, Jamaica, regarding childhood diarrhea and dehydration in order to determine if limited caregiver knowledge about the prevention and treatment of diarrhea and dehydration puts children at increased risk of presenting at the hospital for these concerns.

Methods. The study was an observational case-control study conducted between February 1997 and May 1997 at Bustamante Hospital for Children in Kingston. Convenience sampling was used and data were collected by face-to-face interviews with two groups of caregivers of children under 5 years of age. One group $(\mathrm{n}=117)$ presented with children with acute gastroenteritis, and the other group $(\mathrm{n}=98)$ presented with acute concerns unrelated to gastroenteritis. While 197 of the 215 caregivers interviewed were the mother of a child, there were also 9 guardians, 5 fathers, and 4 grandmothers in the sample.

Results. The mean caregiver age, level of education, and socioeconomic status were similar for the two groups. The caregivers in the gastroenteritis group were more likely to present with younger children and to have less convenient access to running water or a refrigerator. Children of caregivers who had never heard of oral rehydration therapy were at increased risk of presenting with gastroenteritis and dehydration (odds ratio [OR], 4.6; 95\% confidence interval [CI], 1.8-11.7), as were children of caregivers with low knowledge scores about the prevention and treatment of diarrhea and dehydration (OR, 3.7; 95\% CI, 1.6-8.8). Another independent risk factor was a caregiver's poor sense of self-reliance in managing a child's diarrhea (OR, 2.3; 95\% CI, 1.1-4.9).

Conclusions. These findings highlight a need to enhance educational efforts that will empower caregivers to protect their children from diarrhea-associated morbidity and mortality.

Key words Diarrhea; oral rehydration; patient education; infant health; knowledge, attitudes, practices.

In 1978 an editorial in the journal The Lancet hailed oral rehydration therapy (ORT) as "potentially the most impor-

\footnotetext{
1 University of California at Berkeley-University of California at San Francisco Joint Medical Program, University of California, San Francisco, California, United States of America. Send correspondence to: Lela Bachrach, 1375 8th Ave., San Francisco, California 94122, United States of America; telephone: (415) 664-0391; e-mail: lbachra@itsa.ucsf.edu

2 University of the West Indies, Tropical Medicine Research Institute, Epidemiology Research Unit, University of the West Indies, Mona, Jamaica.
}

tant medical advance of this century" (1). ORT has been dubbed "an oasis of hope" and "a miracle of modern medicine" because of its low cost and its contribution to saving lives (2). ORT is a well-established therapy for the prevention and treatment of dehydration due to diarrhea, vomiting, and fever. It entails the oral administration of fluid and electrolytes using an appropriate oral rehydration solution (ORS), replacement of ongoing fluid losses with
ORS, and frequent feeding of appropriate foods as soon as dehydration is corrected. The therapy was first used on a large scale in 1971 during the Bangladeshi war of independence, when outbreaks of cholera swept through refugee camps (3). While the death rate from diarrhea in most of the refugee camps was $30 \%$, in the camps where ORT was introduced, the death rate dropped dramatically, to just $1 \%$. Since that time, ORT has been widely cred- 
ited with having saved the lives of millions of children in the developing world $(4,5)$.

Today, an estimated 3 million children under 5 years of age die annually of diarrhea-related dehydration in the developing world (6). In Jamaica, gastroenteritis is the leading cause for hospitalization of infants (7), and 25\% of deaths in children under 5 are due to acute diarrheal diseases (8). According to data from the Jamaican Ministry of Health (8), 33\% of children under 5 presenting at health facilities are dehydrated. The estimated proportion of children in the country under 5 with reasonable access to a trained provider of oral rehydration salts who receives adequate supplies is $84 \%$ (9). Nevertheless, the estimated proportion of cases of diarrhea in children under 5 in Jamaica treated with ORS is just $8 \%$, a rate lower than in many other countries of the Caribbean.

Small children with gastroenteritis can become dehydrated very quickly, especially in areas with a hot climate. Mothers and other caregivers play a critical role in the effective management of childhood diarrhea by correctly recognizing when their children have diarrhea, and taking appropriate action. When adequately educated, caregivers can start fluid replacement early in the course of a child's illness in order to prevent dehydration. Ultimately, caregivers are the ones who decide if a child's episode of gastroenteritis warrants a visit to a health facility or if they can manage the episode themselves at home.

The objective of this study was to determine the knowledge, attitudes, and practices of caregivers in Kingston, Jamaica, regarding childhood diarrhea and dehydration and to explore whether either limited caregiver knowledge or caregiver sense of self-reliance in managing diarrhea are risk factors for children to present to the hospital with diarrhea or dehydration. Gaining a better understanding of caregivers' management of childhood diarrhea and the factors that influence their use of ORT will allow health workers as well as caregivers to reduce unnecessary morbidity and mortality from dehydration.

\section{METHODS}

This study was conducted in the acute care department of Bustamante Hospital for Children (BHC), the only dedicated children's hospital in Jamaica. Convenience sampling was used to recruit 215 caregivers of children under 5 years old between February and May of 1997. While 197 of the caregivers (91.6\%) interviewed were the mother of a child, there were also 9 guardians $(4.2 \%), 5$ fathers $(2.3 \%)$, and 4 grandmothers $(1.9 \%)$ in the sample. (As some $98 \%$ of the caregivers were women, in this article we will use "she" rather than "he or she" and "her" rather than "his or her.")

All of the caregivers gave informed consent before they were enrolled in the study. One group of caregivers (the "GE group," $n=117$ ) had come to the hospital with children with acute gastroenteritis, and they were recruited in the oral rehydration room. The other group of caregivers ("nonGE group," $n=98$ ) had brought children to the hospital with acute concerns unrelated to gastroenteritis. These caregivers were recruited in the main waiting area. Because the two groups were recruited in two different waiting areas, the interviewer was not blinded to the caregiver group status, but a standardized questionnaire was used with both groups. All caregivers in the two waiting areas were invited to participate, and the participation rate of caregivers in both groups was over $95 \%$. Most of the $5 \%$ of caregivers who were not included had agreed to participate, but were called to see the doctor in the middle of the interview and did not subsequently return. The caregivers in the GE group tended to remain at the hospital longer than the non-GE group because they stayed for a few hours administering oral rehydration fluids to their children, so a larger number of them were recruited for the study.

The data were collected by means of a questionnaire administered by face-to-face interviews by one of the authors (LRB). (The questionnaire is available from that author). The questionnaire, which utilized a mix of open-ended and close-ended questions, was first piloted at BHC with focus groups of caregivers. Modifications were made so that all of the questions were easily understood.

The questionnaire had background questions asking the caregiver about her age, education, employment status, access to toilet facilities and to running water, and breast-feeding. As a proxy for socioeconomic status (SES), the degree of crowding and the access to sanitation services (toilet facilities and running water) were combined into an SES score (see Appendix of this article for details on scoring). Other questions assessed knowledge of the prevention and treatment of diarrhea and dehydration, and a knowledge score was calculated, with a higher score indicating more correct answers. Additional questions, on the degree to which the caregiver felt that she could care for her child during an acute diarrheal episode rather than coming to the hospital, were used to determine an "independence score." Those caregivers who felt more selfreliant received a higher independence score. Finally, there were questions on caregiver attitudes and practices regarding the use of over-the-counter medications as well as folk remedies, breast-feeding, and feeding a child with gastroenteritis.

Statistical calculations were done using SPSS for Windows version 8.0.0 software (SPSS, Inc., Chicago, Illinois, United States of America). Bivariate comparisons were performed with oneway analysis of variance (ANOVA) and Pearson correlations. Odds ratios (ORs) are presented with their 95\% confidence intervals (CIs). Multiple linear regressions were used to determine the independent associations between demographic factors and presenting with a child with gastroenteritis.

\section{RESULTS}

Interviews were completed with 215 caregivers of children less than 5 years old (Table 1$)$. One group $(n=117)$ presented with children with acute gastroenteritis, and the other group $(n=$ 
TABLE 1. Comparable characteristics of caregivers presenting at hospital with a child with gastroenteritis ("GE group") and of caregivers presenting at hospital with a child for another acute reason ("Non-GE group"), Kingston, Jamaica, 1997"

\begin{tabular}{|c|c|c|c|c|}
\hline Characteristic & \multicolumn{2}{|c|}{$\begin{array}{l}\text { GE group } \\
(n=117)\end{array}$} & \multicolumn{2}{|c|}{$\begin{array}{l}\text { Non-GE group } \\
\quad(n=98)\end{array}$} \\
\hline \multicolumn{5}{|l|}{ Caregiver age (yr) (no., \%) } \\
\hline $16-20$ & 25 & 21 & 10 & 10 \\
\hline $21-25$ & 33 & 28 & 31 & 32 \\
\hline $26-30$ & 31 & 27 & 30 & 31 \\
\hline $31-35$ & 15 & 13 & 9 & 9 \\
\hline $36-65$ & 13 & 11 & 18 & 18 \\
\hline \multicolumn{5}{|l|}{$\begin{array}{l}\text { Highest educational level } \\
\text { completed by caregiver (no., \%) }\end{array}$} \\
\hline Primary or less & 23 & 20 & 12 & 12 \\
\hline Junior secondary & 35 & 30 & 28 & 29 \\
\hline Secondary & 57 & 49 & 48 & 49 \\
\hline Tertiary & 2 & 2 & 10 & 10 \\
\hline Child's father living in home (no., \%) & 53 & 45 & 39 & 40 \\
\hline \multicolumn{5}{|l|}{ Time to reach hospital (min) (no., \%) } \\
\hline$<15$ & 16 & 14 & 14 & 17 \\
\hline $15-29$ & 40 & 36 & 26 & 33 \\
\hline $30-59$ & 36 & 32 & 23 & 29 \\
\hline $60-119$ & 16 & 14 & 14 & 17 \\
\hline$>120$ & 5 & 4 & 3 & 4 \\
\hline \multicolumn{5}{|l|}{ Toilet facilities (no., \%) } \\
\hline No toilet facilities/pit & 18 & 16 & 17 & 17 \\
\hline Outside flush toilet & 39 & 33 & 17 & 17 \\
\hline Inside flush toilet & 60 & 51 & 64 & 66 \\
\hline \multicolumn{5}{|l|}{ Crowding (people/room) (no., \%) } \\
\hline$<1$ & 13 & 11 & 18 & 18 \\
\hline $1-2.0$ & 50 & 43 & 45 & 46 \\
\hline $2.1-4$ & 45 & 38 & 28 & 29 \\
\hline$>4.1$ & 9 & 8 & 7 & 7 \\
\hline Mean crowding (people/room) & 2.1 & & 1.9 & \\
\hline SES score (mean, SD)b & 12.3 & 3.8 & 13.6 & 3.9 \\
\hline
\end{tabular}

${ }^{a}$ None of the $P$ values for the comparisons of the two groups was significant at the $P<0.05$ level, according to one-way analysis of variance.

b Socioeconomic status (SES) score was based on a sum of the crowding score and the sanitation score, with a range of 1 to 18 and with more points given to families with higher socioeconomic status (see Appendix of article for details); SD = standard deviation.

98) presented with acute concerns unrelated to gastroenteritis. Most caregivers $(59 \%)$ were in the age group of 21-30 years, with a range of 16 to 65 years old (the few fathers and grandmothers in the sample accounted for the caregivers in the upper age range). The mean age, highest level of education completed, and socioeconomic status were similar for the caregivers in the GE group and those in the nonGE group. The two groups were also similar in terms of post-school training in areas intended to lead to greater employment opportunities, such as clerical/typing skills and crafts/sewing training (data not shown). There were also no significant differences between the two groups in terms of access to toilet facilities, presence of the child's father in the home, or degree of crowding in the home.

The range in children's age was 2-60 months. As shown in Table 2, the children in the GE group were significantly younger (mean age of 20.8 months) than those in the non-GE group (mean of 34.4 months). The GE group families were less likely to have convenient access to running water or to a refrigerator. The caregivers in the GE group were more likely to be unemployed, and they also had more children under age 5 in the home.
All of the children in the GE group presented with gastroenteritis, with $38 \%$ of them with diarrhea, $32 \%$ with vomiting, and 30\% with both diarrhea and vomiting. The children in the nonGE group presented with asthma, broken arms, dog bites, swallowed coins, rashes, objects stuck in the child's nose, or other nongastrointestinal concerns.

While $94 \%$ of the caregivers in the non-GE group had heard of ORS before coming to the hospital, only $76 \%$ of the GE caregivers had (one-way ANOVA, $P<0.001)$. Of the caregivers who already knew of ORS, most of them $(65 \%)$ said they had learned about it at a clinic or hospital, 17\% from a relative, $15 \%$ from a friend, and none had heard about ORS through the media (television, radio, or newspapers). Before bringing their child to the hospital, $66 \%$ of the caregivers in the GE group had given the child extra fluids, but ORS was used by only $8 \%$ of the caregivers. Juice (51\%) and "tea" (usually commercial black teas or mint tea) $(32 \%)$ were given most frequently, followed by breast milk (16\%), infant formula $(9 \%)$, water $(9 \%)$, and coconut water $(8 \%)$ ) (some caregivers had used more than one type of fluid, so the total is greater than $100 \%$ ). Coconut water was given as often as ORS. A few caregivers reported either giving a mixture containing table salt and water $(4 \%)$ or providing a soft drink $(3 \%)$. Fifty caregivers in the GE group $(43 \%)$ did not know any signs or symptoms of serious diarrhea or dehydration, as compared to 28 caregivers in the non-GE group (29\%).

There was a statistical difference that was highly significant $(P<0.001$, according to the one-way ANOVA) between the two groups in their mean knowledge score, with the caregivers in the GE group (mean knowledge score 3.7, standard deviation [SD] 2.9) knowing less about the appropriate management of childhood diarrhea and the prevention and treatment of dehydration than did the caregivers in the non-GE group (mean knowledge score 5.4, SD 2.5). The mean independence score was also lower $(P<0.01$, one-way ANOVA) for the GE group (mean independence score 15.1, SD 
TABLE 2. Differing characteristics of caregivers presenting at hospital with a child with gastroenteritis ("GE group") and of caregivers presenting at hospital with a child for another acute reason ("Non-GE group"), Kingston, Jamaica, 1997"

\begin{tabular}{|c|c|c|c|c|c|}
\hline \multirow{2}{*}{$\frac{\text { Characteristic }}{\text { Age of child }(\mathrm{mo})(\text { mean, SD) }}$} & \multicolumn{2}{|c|}{$\begin{array}{l}\text { GE group } \\
(n=117)\end{array}$} & \multicolumn{2}{|c|}{$\begin{array}{l}\text { Non-GE group } \\
\quad(n=98)\end{array}$} & \multirow{2}{*}{$\frac{P \text { value }^{\mathrm{b}}}{0.0001}$} \\
\hline & 20.8 & 15.7 & 34.4 & 20.9 & \\
\hline Water facilities (no., \%) & & & & & 0.005 \\
\hline No running water/carry water & 15 & 13 & 9 & 9 & \\
\hline Spigot in yard & 45 & 38 & 24 & 24 & \\
\hline Spigot inside home & 57 & 49 & 65 & 66 & \\
\hline Refrigerator (no., \%) & & & & & 0.047 \\
\hline Yes & 79 & 67 & 78 & 80 & \\
\hline Employment status of caregiver (no., \%) & & & & & 0.020 \\
\hline Not working & 78 & 67 & 51 & 52 & \\
\hline Part-time & 6 & 5 & 5 & 5 & \\
\hline Full-time & 33 & 28 & 41 & 42 & \\
\hline No. of children $<5$ at home (mean, SD) & 1.6 & 0.7 & 1.3 & 0.7 & 0.026 \\
\hline
\end{tabular}

a All 215 caregivers were included in the analysis. They were asked to answer the questions in reference to the child's home environment, such as whether the home where the child was living had a refrigerator.

b $P$ value according to one-way analysis of variance.

${ }^{c} \mathrm{SD}=$ standard deviation.
4.2) as compared to the non-GE group (mean independence score 16.9, SD 4.2 ), indicating that the GE group caregivers felt less competent in their ability to take care of a child during an episode of gastroenteritis. The nonGE caregivers were more likely to believe that they could prepare rehydration fluid for their child that was just as good as the fluid provided in the hospital.

A variety of risk factors for presenting with a child with gastroenteritis and/or dehydration were identified (Table 3). Compared to children who were breast-fed, children who were not breast-fed were more likely to present with acute gastroenteritis. Similarly, when a caregiver had never heard of ORS before, had a low knowledge score, or had a low independence score, her child was at greater risk.

Multiple linear regression analyses showed no evidence that caregiver age, education, or socioeconomic status were related to the caregiver knowledge score (Table 4). However, presenting with a child with gastroenteritis was predictive of a low knowledge score $(P=0.0001)$.
With respect to the independence score, the same three factorscaregiver age, education, and socioeconomic status-were again not statistically significant predictors of the score (Table 5). However, those caregivers presenting with a child with gastroenteritis were significantly less likely to feel self-reliant in managing diarrhea or dehydration $(P=0.003)$.

Overall, $60 \%$ of the caregivers said they felt it was easy to access packs of ORS. Caregivers typically obtained
ORS either over the counter at pharmacies or at health centers. Most caregivers $(78 \%)$ said that their child did not like the taste of ORS. Ninety-one percent of the caregivers agreed that the purpose of ORS was to replace fluids lost in diarrhea or vomiting. However, $84 \%$ thought that ORS was supposed to stop diarrhea or vomiting, and $42 \%$ even thought that ORS could prevent diarrhea.

Many Jamaican caregivers believe that if a baby swallows his or her sawater" - that this can cause diarrhea. In our study, $82 \%$ of the caregivers interviewed thought teething water could cause diarrhea. Another Jamaican folk belief, which used to be more prevalent, was that it was beneficial to give a child with diarrhea a laxative or "washout," usually in the form of a purgative bush tea (10) to "flush out" the child's system. That belief was shared by $9 \%$ of the GE caregivers and $2 \%$ of the non-GE caregivers. Over half of the caregivers $(62 \%)$ thought that coconut water, the fluid in immature coconuts, was a better treatment for a child with diarrhea than an over-the-counter antidiarrheal or antimotility medication.

The caregivers in the non-GE group were significantly more likely $(P<0.01$, one-way ANOVA) to have breast-fed their children (98\%) than those in the GE group (89\%). For the caregivers who did breast-feed, the mean duration of breast-feeding was significantly longer for the non-GE group caregivers liva during teething-their "teething

TABLE 3. Predictors of presenting with a child with gastroenteritis and/or dehydration, Kingston, Jamaica, 1997

\begin{tabular}{lccc}
\hline \multicolumn{1}{c}{ Risk factor } & Odds ratio & $95 \% \mathrm{Cl}^{\mathrm{a}}$ & $P$ value $^{\mathrm{b}}$ \\
\hline Child not breast-fed $_{\text {Caregiver has never heard of ORS }}^{\mathrm{c}}$ & 6.1 & $1.3-27.5$ & 0.009 \\
Low knowledge score $^{\mathrm{d}}$ & 4.6 & $1.8-11.7$ & 0.001 \\
Low independence score $^{\mathrm{e}}$ & 3.7 & $1.6-8.8$ & 0.002 \\
\hline
\end{tabular}

${ }^{\mathrm{a}} \mathrm{Cl}=$ confidence interval.

b $P$ value is from Pearson chi-square test.

${ }^{\mathrm{C}} \mathrm{ORS}=$ oral rehydration solution.

d Low knowledge score meant fewer correct answers regarding proper management of childhood diarrhea or dehydration.

e Low independence score meant caregiver felt less capable of managing a child's diarrhea or dehydration without the assistance of health workers. 
TABLE 4. Multiple linear regression analysis of caregivers' score for knowledge of appropriate management of childhood diarrhea, Kingston, Jamaica, $1997^{\mathrm{a}}$ b

\begin{tabular}{lccc}
\hline \multicolumn{1}{c}{ Predictor } & $\begin{array}{c}\text { Standardized } \\
\text { regression } \\
\text { coefficient }\end{array}$ & $\begin{array}{c}\text { Pearson } \\
\text { correlation }\end{array}$ & $P$ value \\
\hline Presenting with gastroenteritis & -0.282 & -0.294 & 0.0001 \\
Caregiver age & 0.041 & 0.052 & 0.554 \\
Caregiver education & 0.085 & 0.103 & 0.249 \\
Socioeconomic status & -0.021 & 0.060 & 0.773 \\
\hline
\end{tabular}

a $\mathrm{A}$ higher knowledge score indicated more correct answers given regarding proper management of childhood diarrhea or dehydration. This analysis shows the prediction for higher knowledge scores

${ }^{b} R^{2}=0.093$ for this analysis (that is, these predictors account for only $9.3 \%$ of the variability in the knowledge score).

TABLE 5. Multiple linear regression analysis of independence score, for the degree to which caregivers felt they could care for an acute diarrheal episode independently rather than bringing a child in to a health facility, Kingston, Jamaica, 1997a, b

\begin{tabular}{lccc}
\hline \multicolumn{1}{c}{ Predictor } & $\begin{array}{c}\text { Standardized } \\
\text { regression } \\
\text { coefficient }\end{array}$ & $\begin{array}{c}\text { Pearson } \\
\text { correlation }\end{array}$ & $P$ value \\
\hline Presenting with gastroenteritis & -0.211 & -0.204 & 0.003 \\
Caregiver age & 0.038 & 0.058 & 0.591 \\
Caregiver education & 0.012 & 0.000 & 0.875 \\
Socioeconomic status & -0.078 & -0.037 & 0.290 \\
\hline
\end{tabular}

a This analysis is a prediction of a higher independence score, meaning a caregiver felt more capable of managing a child's diarrhea or dehydration without the assistance of health workers.

${ }^{b} R^{2}=0.048$ for this analysis (that is, these predictors account for only $4.8 \%$ of the variability in independence score).

(mean of 10.4 months, SD of 8.3 months) than it was for the GE caregivers (6.4 months, SD of 4.5 months) $(P<0.001$, one-way ANOVA) Thirtysix percent of the GE caregivers had given their child an antidiarrheal medication such as Pepto-Bismol (bismuth subsalicylate), which alters intestinal secretion, or antimotility opioids, such as Lomotil (diphenoxylate/atropine) or Imodium (loperamide), to try to stop the diarrhea before coming to the hospital.

Many caregivers said they believed that nutritional practices should be changed when a child has diarrhea. Both groups had comparable answers regarding food, with $38 \%$ of the caregivers saying that a child with diarrhea should not be given solid food, $25 \%$ saying that no food should be given at all, and $31 \%$ saying no milk should be given. When asked if a baby with diarrhea that was still nursing should be breast-fed, $20 \%$ of the GE group caregivers said to stop breastfeeding and $8 \%$ of the non-GE group said to stop breast-feeding.

\section{DISCUSSION}

This study highlights that children of caregivers in Kingston, Jamaica, with limited knowledge about ORT were at increased risk of presenting at the hospital with a child with acute gastroenteritis and/or dehydration, even when adjusted for potential confounders such as caregiver age, educational status, and socioeconomic status. If she had a low sense of selfreliance in managing her child's gastroenteritis, independent of her actual knowledge on the topic, her child was also at increased risk. We encountered a great deal of misinformation circulating regarding the prevention and treatment of gastroenteritis, based both on outdated recommendations from Western medicine and on Jamaican folk beliefs. In addition, many caregivers had unrealistic expectations of ORS, which could understandably lead to disillusionment with its use.

While in the past, medical professionals thought that it was important to "rest the gut" during diarrhea, this notion has since been discredited (11). Studies have shown that the resting gut rapidly atrophies, such that levels of digestive enzymes fall and the absorption of nutrients worsens. Appropriate feeding is now recognized as a crucial element of ORT $(12,13)$, especially in populations at risk for malnutrition. And while Jamaica had reduced its prevalence of malnourished children to $3.9 \%$ by the year 2000, there are millions more children in developing countries who are still malnourished.

It is worrisome that many of the Jamaican caregivers we interviewed spoke of withholding food while their child had diarrhea. Similarly, past guidelines from the American Academy of Pediatrics recommended that milk and milk products be avoided during diarrhea, while the latest guidelines have reevaluated this advice $(12,13)$. Given that a third of the caregivers we interviewed said not to give milk to a child with diarrhea, health messages need to be updated in Jamaica. One in five of the GE caregivers interviewed had extended the notion of avoiding milk to include breast milk. This is worrisome since nursing infants who are already losing fluids from gastroenteritis are extremely vulnerable to dehydration.

Also of concern was the small group of caregivers who reported giving their children a mixture of table salt and water, presumably intending to substitute for oral rehydration salts, popularly referred to as "the salts" in Jamaica. This substitution is dangerous because it can lead to hypernatremic dehydration. There has been 
much debate about the relative merits of teaching caregivers to make sugarsalt solution for ORT versus using prepackaged ORS (14, 15), and this finding in our study shows that the issue is still up for discussion. Some might conclude from this that certain caregivers prefer to make their own solutions, so they might as well be taught the appropriate recipe. Others could argue that this is a sign that packets of ORS need to be more easily accessible. More work is needed to find out why these caregivers decided to mix salt water for their children. It was notable that before coming to the hospital caregivers in the GE group were just as likely to have used coconut water as ORS when treating a child with gastroenteritis. As coconuts are readily available in Jamaica and coconut water is sterile as long as it is opened without contamination, it may make sense to encourage caregivers to use coconut water as a fluid to prevent dehydration, according to various studies (16-20). For rehydration, however, those same studies have shown that the composition of coconut water varies depending on the stage of maturity of the coconut and is thus not as ideal for this purpose.

Folk beliefs that have challenged health care workers in the past (21) were still evident in our study. A small group of caregivers endorsed the idea of giving a child with gastroenteritis a "washout," or laxative, in the form of a bush tea. While giving a child with gastroenteritis a bush tea may indeed stop the diarrhea, the ensuing dehydration will be far more harmful. When caregivers understand that it is the dehydration and not the diarrhea that is life-threatening, they will be less likely to believe in giving a washout.

The majority of the caregivers interviewed believed that "teething water" causes diarrhea. This can be dangerous if the caregivers assume that teething children who have diarrhea are undergoing a normal phase of development and that no special treatment is needed. It makes sense for caregivers to have observed that teething children are more prone to diarrhea. Children at this age tend to start being weaned and thus lose the protection of breast milk (22). They also may be exposed to food-borne germs, and they are likely crawling around exploring the world via their mouths. Rather than emphasizing the actual etiology of the diarrhea, as health education efforts have done in the past, it might be more useful to teach caregivers to give ORS to prevent and treat dehydration when a child has diarrhea, regardless of its cause.

It was initially puzzling to us to find that although most caregivers in the GE group had heard of ORS, the vast majority of them had not given their children ORS before coming to the hospital. This may be explained by the unrealistic expectations that many caregivers had of ORS. Most caregivers interviewed thought that the ORS would stop their child's diarrhea and/or vomiting, rather than just replacing lost fluids. Over a third of the caregivers said that they thought ORS could prevent a child from getting gastroenteritis. Caregivers may feel disillusioned with ORS if it doesn't perform as they expect, leading to limited use. Over a third of the GE caregivers reported giving their child an overthe-counter opiate or antimotility drug to counteract their child's diarrhea. This was troubling because many studies have shown that these medications should have no role in the management of pediatric diarrhea $(12,13$, 23-25). Of the caregivers who had given their children with gastroenteritis extra fluids before coming to the hospital, most had given juice or sweetened tea. These fluids tend to have too much sugar and not enough salt to be appropriate rehydration fluids (26).

An earlier study in Jamaica (27) found that caregivers in the community were less knowledgeable about ORT than were caregivers who brought their children in to health centers. This is consistent with our finding that most of the caregivers reported having heard about ORT from coming into a health facility. Unfortunately, health workers are frequently overworked and do not have time to counsel caregivers on the prevention and treatment of diarrhea or dehydration. A recent study in South Africa showed that contact with health workers during a period of admission to the pediatric short-stay facility had no impact on the caretakers' knowledge of gastroenteritis or its management (28). Since caregivers spend much time administering rehydration fluids when they come into the hospital and they may be particularly receptive to learning about gastroenteritis when it is an acute issue that they are facing, it seems like a prime opportunity to engage them. Another potentially untapped way of reaching caregivers in Jamaica is through the mass media. It was interesting to note that a preponderance of the caregivers, even those without running water, reported that they had a television. None of them had heard of ORT through the media.

We believe our study is important because it elucidates misinformation circulating concerning ORT and points out some potentially useful educational approaches. One limitation of the study is that the hospital-based sample may not be generalizable. Based on prior studies mentioned above and the fact that most caregivers reported learning about ORS from coming into a health facility, it is plausible that there may be even less knowledge and use of ORS in the total population of caregivers in Jamaica. In addition, since the interviewer was likely to have been perceived as a representative of the medical establishment, caregivers may have tried to give responses that they thought the interviewer would want to hear. For example, the use of home remedies for diarrhea has been categorically discouraged in Jamaica (27), so the caregivers interviewed for our study may have underreported their use. In addition, drawing upon an urban population may have underestimated the number of caregivers using bush teas or other folk remedies, which are more readily available in rural areas. Finally, caregivers bringing in severely dehydrated children in need of intra- 
venous fluids were excluded, as it did not seem appropriate to demand their attention while their children were critically ill. This may have resulted in the exclusion of caregivers with even less knowledge of the prevention and treatment of dehydration.

Our findings have implications on both individual and societal levels. Poverty and suboptimal living conditions are recognized to be mediators of diarrheal diseases $(29,30)$. While caregivers often do not have immediate control over the economic and social factors that put their children at risk of diarrhea, they can have a high degree of control over their children's wellbeing in terms of preventing death from diarrhea-related dehydration if they have access to ORS and know how to use it properly. This study shows that limited knowledge of ORS is a risk factor for gastroenteritisrelated morbidity. It points to some health behaviors that are counterproductive, including wasting limited re- sources on over-the-counter therapies that are not indicated and discontinuing breast-feeding when infants have diarrhea. These detrimental practices can be targeted in health promotion efforts. Caregivers who feel more selfreliant in managing their child's gastroenteritis are more likely to initiate ORS at home and are less likely to end up at the hospital with a dehydrated child. These caregivers who can manage acute gastroenteritis effectively at home also avoid many indirect costs, including missed work and costs of transportation to the hospital. Maximizing access to ORS may help protect children from dehydration. This could be done, for example, by encouraging caregivers to keep packets of ORS on hand at home or by teaching caregivers who are set on mixing their own home fluids the appropriate recipe for sugar-salt solution. The mass media could be used to spread the word about ORT, by teaching caregivers about appropriate feeding practices during gastroenteritis and updating them when health practices change.

On a societal level, Jamaica has had great success with breast-feeding, and this study confirms the country's enviably high rates of breast-feeding. However, diarrheal disease is still a common cause of morbidity among Jamaican children under 5 years of age. It also exerts a heavy burden on the health care system, with a quarter of deaths in this age group being due to acute diarrheal disease. ORT is a simple, effective, and inexpensive treatment modality. Maximizing its use is important at a time when the health budgets of many nations are increasingly stretched. Cost-effectiveness studies have shown that ORT programs, if fully implemented, can lead to tremendous savings (31). Hopefully, by scrutinizing and improving current health promotion efforts in Jamaica and elsewhere, we can work with caregivers to prevent unnecessary suffering caused by diarrhea and dehydration.

\section{REFERENCES}

1. Water with sugar and salt [editorial]. Lancet 1978;2(8084):300-301.

2. Mull J. Oral rehydration therapy: an oasis of hope in the developing world. J Fam Pract 1984;18(3):485-487.

3. Mahalanabis D, Choudhuri AB, Bagchi NG, Bhattacharya AK, Simpson TW. Oral fluid therapy of cholera among Bangladesh refugees. Johns Hopkins Med J 1973;132(4):197205.

4. Hirschhorn N, Greenough WB 3rd. Progress in oral rehydration therapy. Scientific American 1991;264(5):50-56.

5. Bellamy C. State of the world's children. New York: United Nations Children's Fund; 1996.

6. World Health Organization. Division of Child Health and Development interim programme report. Geneva: WHO; 1997.

7. Pan American Health Organization. Jamaica. In: PAHO. Health in the Americas, 1998 edition. Volume II. Washington, D.C.: PAHO; 1998. Pp. 343-355. (PAHO Scientific Publication No. 569).

8. Center for International Health Information. Health statistics report. Kingston, Jamaica: CIHI; 1996.

9. World Health Organization, Programme For Control of Diarrhoeal Diseases. Annual report. Geneva: WHO; 1994.
10. Sobo EJ. One blood: the Jamaican body. Albany, New York, United States: State University of New York Press; 1993

11. Isolauri E, Vesikari T, Saha P, Viander M. Milk versus no milk in rapid refeeding after acute gastroenteritis. J Pediatr Gastroenterol Nutr 1986;5(2):254-261.

12. Nazarian LF. A synopsis of the American Academy of Pediatrics' practice parameter on the management of acute gastroenteritis in young children. Pediatr Rev 1997;18(7):221223.

13. Practice parameter: the management of acute gastroenteritis in young children. American Academy of Pediatrics, Provisional Committee on Quality Improvement, Subcommittee on Acute Gastroenteritis. Pediatrics 1996; 97(3):424-435.

14. Erasmus PS, Harland G, Cox DL, Lyew M, Lindo F. Composition of oral solutions prepared by Jamaican mothers for treatment of diarrhoea. Lancet 1981;1(8220 Pt 1):600601.

15. Cash RA, Keusch GT, Lamstein J. Child health and survival: the UNICEF GOBI-FFF Program. London; Wolfeboro, New Hampshire, United States: Croom Helm; 1987.

16. Kuberski T. Appropriate technology: coconut water for the oral rehydration of childhood diarrhoeas. N Z Med J 1980;91(660):390-392.
17. Cutting WA. Coconut water and home rehydration. Lancet 1986;2(8507):640-641.

18. Cooper ES. Coconut water. Lancet 1986; 2(8501):281.

19. Chavalittamrong B, Pidatcha P, Thavisri U Electrolytes, sugar, calories, osmolarity and $\mathrm{pH}$ of beverages and coconut water. Southeast Asian J Trop Med Public Health 1982; 13(3):427-431.

20. Karalus J. Coconut water and rehydration. N Z Med J 1980;92(664):67.

21. MacCormack C, Draper A. Promoting ORT correctly. Dialogue on Diarrhoea 1985;23:5.

22. Coreil J, Price L, Barkey N. Recognition and management of teething diarrhea among Florida pediatricians. Clinical Pediatrics 1995; 34(11):591-598.

23. World Health Organization. The rational use of drugs in the management of acute diarrhoea in children. Geneva: WHO; 1990.

24. Bhutta TI, Tahir, KI. Loperamide poisoning in children. Lancet 1990;335(8685):363.

25. Minton NA, Smith, PG. Loperamide toxicity in a child after a single dose. Br Med J (Clin Res Ed) 1987;294(6584):1383.

26. Snyder, JD. Evaluation and treatment of diarrhea. Semin Gastrointest Dis 1994;5(1):47-52.

27. van der Geest $S$, Whyte SR, eds. The context of medicines in developing countries. Studies in pharmaceutical anthropology. Dordrecht, the 
Netherlands; Boston, Massachusetts, United States: Kluwer Academic Publishers; 1988. (Culture, Illness and Healing Book Series Volume 12).

28. Mawela MP, de Villiers FP. The effect of admission on oral rehydration-related knowledge. Ann Trop Paediatr 1999;19(1):75-81.
29. Grant J. State of the world's children. New York: United Nations Children's Fund; 1994.

30. Grant J. State of the world's children. New York: United Nation's Children's Fund: 1993.

31. Ladinsky M, Lehmann H, Santosham M. The cost effectiveness of oral rehydration therapy for U.S. children with acute diarrhea. Med Interface 1996;9(10):113-119.

Manuscript received 17 October 2001. Revised version accepted for publication on 28 February 2002.

\section{APPENDIX 1. Scoring}

Knowledge score

There were nine questions on knowledge related to management of childhood diarrhea. The possible range of scores was -9 to 9 . If a question was answered correctly, 1 point was awarded. For a wrong answer, 1 point was taken away. No points were gained or lost if the caregiver said she didn't know the answer.

\section{Independence score}

There were five questions on the degree to which a caregiver felt she could care for an acute diarrheal episode independently rather than bringing a child in to a health facility. A standard Likert scale (1 to 5 points) was used for each of the five questions. The caregivers with higher independence scores believed more strongly that they could care for a child with diarrhea on their own rather than needing to bring the child to the hospital. The total range for this score was 5 to 25 .

\section{Crowding score}

The number of people per room was categorized into 6 groups, with a range 1 to 6 . The most crowded category received 1 point, and the least crowded got 6 points.

\begin{abstract}
Sanitation score
The sanitation score is the sum of the toilet score and of water score. The range is 0 to 6 points for each of those two scores, for a maximum possible sanitation score of 12 points. The toilet scoring and the water scoring are as follows, for having, respectively: own inside flush toilet/own inside pipe for water, 6 points each; shared inside flush toilet/own inside pipe for water, 5 points each; own outside flush toilet/shared inside pipe for water, 4 points each; shared outside flush toilet/own pipe in yard, 3 points each; own pit toilet/shared pipe in yard, 2 points each; shared pit toilet/shared pipe outside yard, 1 point each; no toilet facilities/carry water from stream or well, 0 points each.
\end{abstract}

\section{Socioeconomic status score}

The sum of the crowding score and the sanitation score was used as a proxy for socioeconomic status. The possible range was 1 to 18 , with more points given to families with higher socioeconomic status.

RESUMEN Objetivos. Estudiar los conocimientos, actitudes y prácticas de los cuidadores hacia la diarrea infantil y la deshidratación en Kingston, Jamaica, con el fin de determinar si sus escasos conocimientos sobre la prevención y el tratamiento de la diarrea y la deshidrat-

Conocimientos, actitudes y prácticas de los cuidadores hacia la diarrea infantil y la deshidratación en Kingston, Jamaica ación hacen que los niños corran mayor riesgo de hospitalización por estos problemas. Métodos. Se realizó un estudio observacional de casos y controles entre febrero y mayo de 1997 en el Hospital Infantil Bustamante de Kingston. Se usó una muestra de conveniencia de niños de menos de 5 años y los datos fueron recogidos mediante entrevistas personales con los cuidadores de los dos grupos de niños. Un grupo estaba formado por 117 niños con gastroenteritis aguda, y el otro por 98 niños con problemas agudos no relacionados con la gastroenteritis. De los 215 cuidadores entrevistados, 197 eran las madres, 9 eran tutores, 5 eran los padres y 4 eran las abuelas.

Resultados. La media etaria de los cuidadores, su nivel educacional y su estatus socioeconómico eran similares en los dos grupos. Los cuidadores del grupo de niños con gastroenteritis tenían niños más pequeños y menos acceso al agua corriente y a frigoríficos. Los niños cuyos cuidadores nunca habían oído hablar de la rehidratación oral tenían mayor riesgo de presentar gastroenteritis y deshidratación [razón de posibilidades (odds ratio: OR): 4,6; intervalo de confianza del 95\% (IC95): 1,8-11,7], al igual que los niños cuyos cuidadores tenían escasos conocimientos sobre la prevención y el tratamiento de la diarrea y la deshidratación (OR: 3,7; IC95: 1,6-8,8). Otro factor de riesgo independiente fue la poca confianza del cuidador en su propia capacidad para tratar la diarrea del niño (OR: 2,3; IC95: 1,1-4,9).

Conclusiones. Estos resultados destacan la necesidad de incrementar los esfuerzos informativos que les permitan a los cuidadores proteger a los niños de la morbilidad y la mortalidad relacionadas con la diarrea. 